\title{
Factors Associated With the General Public Knowledge and Awareness of Cardiovascular Diseases and its Risk Factors in Penang - Malaysia
}

\author{
Arwa M. Amin ${ }^{1}$, Hamza Mostafa ${ }^{2}$, Azmi Sarriff ${ }^{3}$ \\ ${ }^{1}$ Master of Pharmacy in Clinical Pharmacy \\ ${ }^{2}$ MSc of Clinical Pharmacy \\ ${ }^{3}$ PharmD, Associate Professor \& Chairman, Discipline of Clinical Pharmacy \\ ${ }^{1,2,3}$ School of Pharmaceutical Sciences, Universiti Sains Malaysia (USM), 11800 Minden, Penang, Malaysia
}

\begin{abstract}
:
Background: Cardiovascular diseases(CVDs) are the top of the ten causes of hospital deaths in Malaysia. Increasing knowledge and awareness on CVDs and its risk factors is crucial for the prevention of CVDs. Identification of factors which are associated with the knowledge and awareness is important for the proper design of future awareness programs.

Objectives: This study was carried out to find out factors which are associated with the current knowledge and awareness of cardiovascular diseases (CVDs) and its risk factors among the general public in PenangMalaysia.

Method: Four hundred and fifty-six (456) from the general public participated in the study by filling a structured questionnaire offered in three languages, English, Malay and Chinese. The knowledge and the awareness scores were computed as continuous variables then simple liner regression (SLR) followed by general linear regression (GLR) were used to find factors associated with the levels of knowledge and awareness.

Findings: The GLR final model revealed that the knowledge and awareness of CVDs and its risk factors was associated with the level of education, the previous attendance of health campaign on CVDs and having any CVDs or family history of CVDs.

Conclusion: The study provides insights into factors associated with the knowledge and awareness of CVDs and its risk factors among the general public. Tailored awareness programs are required to address specific demographic groups of the general public.
\end{abstract}

KEYWORDS - Cardiovascular diseases, Knowledge, Awareness, Risk factors, Public Health, Malaysia, Community Pharmacist

\section{INTRODUCTION}

Cardiovascular diseases (CVDs) are fatal circulatory diseases. Deaths due to CVDs overwhelms the developed and developing countries [1,2]. However, developing countries shows higher increase in CVDs deaths. In Malaysia, CVDs represent the first of ten leading causes of deaths in governmental and private hospitals, and the fifth cause of hospitalization [3]. These alarming data shed light on the importance of CVDs prevention as a public health concern. Unfortunately, a major event of cardiovascular disease can happen suddenly without prior obvious symptoms [4]. Therefore, patients with major circulatory event usually present late to the hospital. An early sign or symptom as tongue numbness or heart burn could be the imperative warning symptom of heart attack. Nevertheless, these warning symptoms might not be known to every patient. Furthermore, there are several risk factors which can lead to cardiovascular diseases. Some of these risk factors are non modifiable such as family history of CVDs and congenital dyslipidemia. Other risk factors are modifiable such as lifestyle habits, diet and obesity [5-7]. For instance, the metabolic syndrome which is a group of risk factors such as central obesity, insulin resistance, physical inactivity, hypertension and genetic factors, if present together in one person may lead to CVDs as coronary heart disease (CHD) and stroke [8]. Strikingly, these risk factors increased globally [9, 10]. Similarly in Malaysia [11-13]. Mohamud et al. (2011) indicated high prevalence of metabolic syndrome in Malaysia. Abdominal obesity was highly prevalent in Indians, hypertension was highly prevalent in Malays particularly the males and dyslipidemia was highly prevalent in Chinese [11]. The results of such scrutinies are in line with the increase of deaths due to CVDs which can clearly reflect the growing of devastating public health problem. 
A proper control of the modifiable risk factors can play a vital role in preventing CVDs. To achieve this goal, it is imperative to increase the general public awareness on these risk factors. However, there's uncertainty on the factors associated with the general public knowledge and awareness on CVDs and its risk factors. An estimation of these factors is required to properly design the future awareness programs. This will help to plan and prepare the informative content, the material and the way to deliver the information effectively. Moreover, an estimation of the factors associated with the awareness can help to find the demographic groups which have limited awareness and hence targeting them with special awareness programs.

Concise review and update of the literature from high income countries revealed consistency with little controversy. Thompson (1998) in the heart European leader panel (HELP) study group of five European countries reported the results of surveying the awareness and attitudes on CHD among the general public, high risk public, and patients post myocardial infarction and their family members. It was found that although participants were having reasonable knowledge about CHD they don't act upon their knowledge [14]. Bush et al. (2008) examined the knowledge and awareness of peripheral vascular disease (PVD) among women categorized to three risk levels of CVDs; low, moderate and high. He asserted that the knowledge was low regardless of the risk level [15]. Kandula et al. (2010) detected knowledge gaps and misconceptions about CHD among US Indians and Pakistanis. The level of education was positively associated with the level of knowledge [16]. Lambert et al. (2012) investigated the relationship between the knowledge and the risk of heart attack and stroke in the emergency department in a suburban, public tertiary-care academic medical center in US. He found that people having high risk score had low knowledge level [17].

In the low and middle income countries the studies which focus on finding factors associated with the general public knowledge on CVDs and its risk factors are little. Jafary et al. (2005) found that the education level, income and residence are positively associated with the knowledge on CHD in Pakistan. Similar studies in India and Jordan indicated the same association [18, 19]. Yahya et al. (2012) found positive association between knowledge, attitude and practice independent of socio-demographic factors among female patients in primary care clinic in Kelantan- Malaysia. However, to date there is no published data estimating factors associated with the knowledge and awareness on CVDs and its risk factors among the general public in Malaysia regardless of their gender.The state of Penang in the north west of Malaysia has the privilege of ethnic and culture diversity. This can give better exploration of different demographic factors. The objective of this study is to find factors associated with the knowledge and awareness on CVDs and its risk factors among the general public in Penang, Malaysia.

\section{MATERIALS AND METHODS \\ STUDY DESIGN, SUBJECTS AND METHOD}

This was a cross-sectional study using self-administered questionnaire. The study sample was from the general public residing in the state of Penang, Malaysia. A target sample size of 448 has been set based on the sample size of similar study conducted on females in the state of Kelantan, Malaysia [20]. The inclusion criteria were male and female older than 18 years old, can read and fill the questionnaire and agreed to participate in the study. To exclude any bias in the questionnaire's answers, subjects who has medical background (i.e., doctors, pharmacists, paramedics and nurses) or their direct family members were excluded. The study have been approved by the Joint Ethics Committee of the School of Pharmaceutical Sciences, USM - Hospital Lam Wah Ee.

The collection of data had taken place over three months, from November 2012 to January 2013. The study researchers approached the general public in several public places such as shopping malls, bus stations and mosques. After explaining the study objectives and the procedure of filling the questionnaire, subjects who were willing to participate in the study signed the consent form and filled the questionnaire. The filling of the questionnaire required from 7 to 10 minutes.

\section{QUESTIONNAIRE DEVELOPMENT AND PILOT STUDY}

The questionnaire's questions were close ended. The questionnaire's content was validated and appraised by an expert panel from the school of pharmaceutical sciences-USM. The questionnaire was developed in English then had been translated into Malay and Chinese. A re-back translation was used to ensure the accuracy of translation. The questionnaire consisted of four parts. The first part addressed participant's demographics and self-reported clinical data. The second and third parts aimed to evaluate the participant's knowledge on CVDs and his awareness of CVDs risk factors, respectively. Lastly, the fourth part assessed the general public perception on the role of community pharmacists in the management and prevention of CVDs and the favored source which the general public prefer to get health information.

To pretest the questionnaire's reliability, the questionnaire was piloted in 20 participants from the general public. The results of the pilot study were not included in the final results. Using the statistical software for social sciences SPSS (Version 20), the cronbach's alpha of the piloted questionnaires were $0.71,0.72$ and 0.82 for the knowledge, the awareness and the perception on the role of community pharmacists parts, respectively. Cronbach's alpha of 0.7 have been identified to be the lowest acceptable cronbach's alpha [21]. 


\section{SCORING AND DATA ANALYSIS}

Each question in the knowledge and the awareness parts was assigned a score of one where the maximum total score of each part was computed as continuous variable and was set 13 for the knowledge and 14 for the awareness.

Upon the completion of data collection, the responses of the participants were coded and uploaded to (SPSS, version 20) software. The data has been explored and refined before the analyses. The mean and the standard deviation was calculated for the continuous variables and frequencies for categorical variables. Descriptive statistics was used to analyse the demographic data. One way ANOVA and Tukey HSD tests were used to test the significance of difference among some demographic groups. After checking the assumptions, the simple linear regression (SLR) was used to find factors which are significantly associated with knowledge and awareness. To conduct the general linear regression (GLR), factors with $\mathrm{p}$ value less than 0.25 in SLR were included to find the final model. The fit of the final model was checked for the achievement of all required assumptions of normality, multi-colinearity, outliers, homoscedasticity and the independence of residuals. The significance level was defined as $\mathrm{P}<0.05$.

\section{RESULTS}

\section{DEMOGRAPHICS AND CLINICAL CHARACTERISTICS OF THE PARTICIPANTS}

The total number of questionnaires collected from different sites in Penang was 456. The mean and the standard deviation (SD) of the age were 43 and 14.25 years old, respectively. The male participants represented 55.7\%. The Chinese were $47 \%$, the Malay were $38.8 \%$, and the Indians were $9 \%$. Of the participants, almost $85 \%$ had at least diploma, $71.5 \%$ were employed and 52\% were earning more than RM3000 income. Smokers were $31.6 \%$ while alcohol drinkers were $36.2 \%$. Of the participants, $46.3 \%$ reported having family history of one or more of CVDs and/or diabetes where hypertension was the highest reported family history. Around $25 \%$ of the participants reported that they have one or more of the following chronic diseases: hypertension, high cholesterol and diabetes, where hypertension was the highest reported chronic disease also.

The majority of the participants reported that they had never attended health campaign on heart disease or CVDs. More than half reported that they had never or rarely paid attention to eat healthy diet, quarter reported they usually don't practice exercise (at least 30 minutes once weekly) and one fifth reported they are overweight.

\section{KNOWLEDGE AND AWARENESS OF CVDS AND ITS RISK FACTORS}

The mean and SD of total knowledge score was 6.5 and 3.3, respectively. The total awareness score were 8 and 3.4 , respectively. From the participants, $87.3 \%, 77.0 \%$ and $74.1 \%$ were able to indicate typical symptoms of heart attack such as chest discomfort, faster heart beats and shortness of breath, consequently. However, $31.8 \%, 17.8 \%$ and $17.5 \%$ were able to identify atypical symptoms such as sweating, heart burn and nausea, consequently. From the participants, $86 \%$, $77.4 \%$ and $63.4 \%$ were able to identify CVDs risk factors such as smoking, old age and hypertension, respectively. In contrast, 52\%, 47,6\% and 30.3\% identified alcohol drinking, obesity and diabetes, respectively.

\section{SIGNIFICANT DIFFERENCES IN KNOWLEDGE AND AWARENESS AMONG SOME DEMOGRAPHIC GROUPS}

Using one way ANOVA then Tukey HSD tests, there was significant difference in the mean of knowledge and awareness among different race of the participants. The Chinese and the Malay showed almost the same mean of knowledge and awareness with no significant difference between them. The Indians showed the lowest mean of knowledge and awareness with significant difference between them and the rest of race groups. Others, Non-Malaysians showed similar knowledge to Malay and Chinese with no significant difference with them but they had the highest mean of awareness with significant difference between them and the rest race groups . Figure 1, shows the mean of knowledge and awareness among race groups.

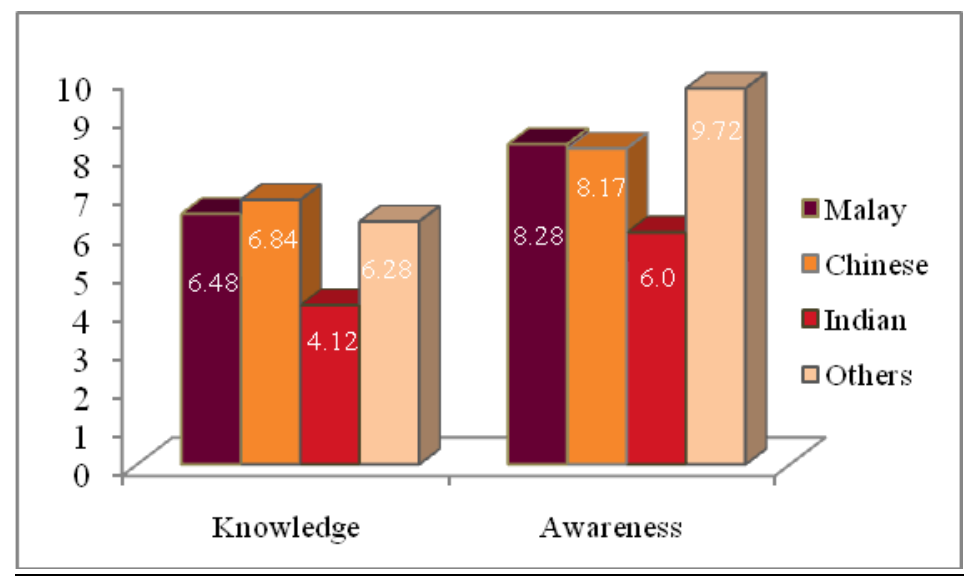

Figure 1: Mean Knowledge and Awareness for Each Race group 
We tested the significance of difference in the means of knowledge and awareness among smokers, ex-smokers and non-smokers, using one way ANOVA then Tukey HSD tests. The smokers and ex-smokers showed almost close means of knowledge and awareness with no significant difference. However, the non-smokers' mean of knowledge and awareness were significantly different from smokers and ex-smokers. Figure 2, shows the mean knowledge and awareness of smokers, ex-smokers and non-smokers.

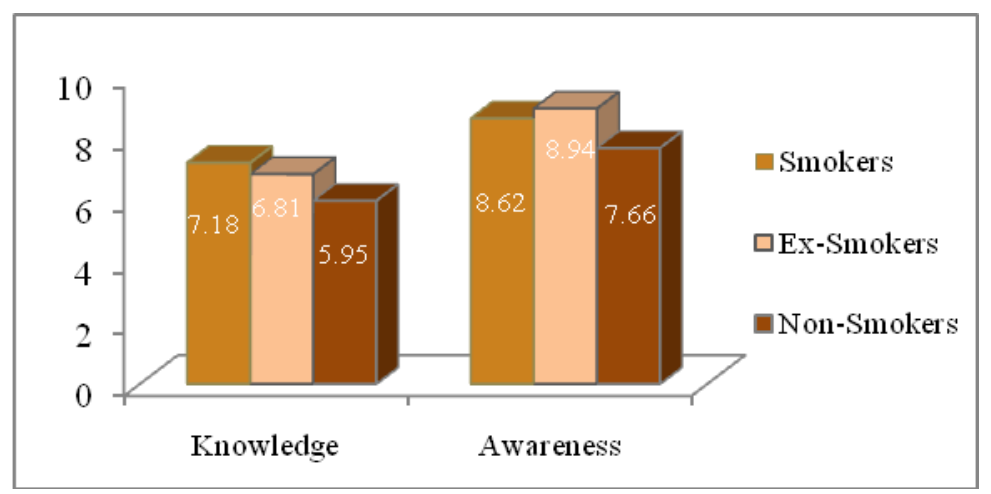

Figure 2: Mean knowledge and awareness of Smokers, Ex-smokers and Non-smokers

\section{THE PERCEPTION ON THE ROLE OF COMMUNITY PHARMACISTS IN THE MANAGEMENT AND PREVENTION OF CVDS AND THE FAVORED SOURCE OF HEALTH INFORMATION}

More than $95 \%$ of the general public reported that they support that community pharmacist should play a role in helping patients manage their prescribed medicine, screen blood pressure, screen blood cholesterol, offer advice on healthy diet and offer advice to help cease smoking. Of the sample, $39 \%$ and $31.6 \%$ reported that television (TV) and internet are their preferred source of health information, respectively.

\section{SIMPLE LINEAR REGRESSION AND GENERAL LINEAR REGRESSION TO FIND FACTORS ASSOCIATED WITH THE KNOWLEDGE AND AWARENESS}

The simple linear regression (SLR) was used to test the association of factors which were theoretically believed to be associated with the knowledge and awareness. In SLR, factors significantly $(\mathrm{P}<0.05)$ associated with the knowledge were drinking alcohol, smoking, self reported weight, education level, younger age, male gender, previous attendance of CVDs' awareness campaign, suffering from any of the CVDs or diabetes, having family history of CVDs or diabetes, practicing exercise and paying attention to eat healthy diet. Except for suffering from any of the CVDs or diabetes $(P=0.052)$, the same factors were significantly associated with the awareness. Factors which were not significantly associated with knowledge were self reported health level $(\mathrm{P}=0.224)$ and income $(\mathrm{P}=0.153)$. Similarly, self reported health level $(\mathrm{P}=$ $0.918)$ and income $(\mathrm{P}=0.068)$ were not significantly associated with awareness.

Factors with $\mathrm{p}$ value less than 0.25 in the SLR were entered in the general linear regression (GLR) to find the final model of predicting factors. In the final model of the knowledge, people will have knowledge on CVDs if they are male, previously attended health campaign on CVDs, and suffer themselves or have family history of any CVDs and/or diabetes. People will have lower knowledge if they are old, have lower level of education, obese and don't pay attention to eat healthy diet. In the final model, there were no association between knowledge and drinking alcohol, income, smoking, practicing exercise and self reported health level.

In the final model of awareness, people are more likely to be aware of CVDs risk factors if they are male, previously attended health campaign on CVDs and suffer themselves or have family history of any CVDs and/or diabetes. People will have lower awareness if they are old, have lower level of education, and don't pay attention to eat healthy diet. There was no association in the final model between awareness and drinking alcohol, income, smoking, practicing exercise, weight and self reported health level. Tables 1 and 2 details the GLR models of knowledge and awareness. 
Factors Associated With The General Public Knowledge and...

Table 1: the General Linear Regression final model of Knowledge Score

\begin{tabular}{|c|c|c|c|c|c|c|}
\hline \multirow[t]{2}{*}{$\begin{array}{c}\text { Demographic and clinical } \\
\text { characteristic }\end{array}$} & \multicolumn{2}{|c|}{$\begin{array}{l}\text { Un-standardized } \\
\text { Coefficients }\end{array}$} & \multirow{2}{*}{$\begin{array}{c}\begin{array}{c}\text { Standardized } \\
\text { Coefficients }\end{array} \\
\text { Beta }\end{array}$} & \multirow{2}{*}{$\begin{array}{c}\text { Significance } \\
\text { P value }\end{array}$} & \multicolumn{2}{|c|}{$\begin{array}{c}\text { Confidence Interval for } \\
\text { B }(95.0 \%)\end{array}$} \\
\hline & B & $\begin{array}{l}\text { Standard } \\
\text { Error }\end{array}$ & & & $\begin{array}{l}\text { Lower } \\
\text { Bound }\end{array}$ & $\begin{array}{l}\text { Upper } \\
\text { Bound }\end{array}$ \\
\hline Age & -.060 & .010 & -.262 & .000 & -.079 & -.041 \\
\hline Gender & -.917 & .257 & -.140 & .000 & -1.422 & -.412 \\
\hline Alcohol drinking & .568 & .290 & .084 & .051 & -.002 & 1.138 \\
\hline Education & 1.285 & .371 & .141 & .001 & .556 & 2.014 \\
\hline $\begin{array}{l}\text { Previous attendance of health } \\
\text { campaign on CVDs }\end{array}$ & 1.894 & .387 & .205 & .000 & 1.133 & 2.655 \\
\hline Weight & -.952 & .345 & -.117 & .006 & -1.631 & -.273 \\
\hline $\begin{array}{l}\text { Having family history of } \\
\text { heart Disease, hypertension, } \\
\text { diabetes or high cholesterol }\end{array}$ & 1.796 & .278 & .275 & .000 & 1.249 & 2.343 \\
\hline $\begin{array}{l}\text { Having any one of the } \\
\text { following chronic diseases: } \\
\text { hypertension or diabetes or } \\
\text { high cholesterol }\end{array}$ & 1.189 & .323 & .159 & .000 & .554 & 1.823 \\
\hline Income & .482 & .279 & .074 & .085 & -.067 & 1.031 \\
\hline $\begin{array}{l}\text { Paying Attention to eat } \\
\text { healthy diet }\end{array}$ & .977 & .267 & .149 & .000 & .452 & 1.501 \\
\hline Smokers Non Smokers & -.207 & .313 & -.029 & .509 & -.821 & .408 \\
\hline Practicing Exercise & .041 & .343 & .005 & .905 & -.634 & .716 \\
\hline Health Level & -.251 & .362 & -.028 & .488 & -.962 & .460 \\
\hline $\begin{array}{ll}\mathrm{R} \text { square } & =0.397 \\
\text { Adjusted R square } & =0.379\end{array}$ & & $\begin{array}{l}\text { of Variance } \\
\text { of Variance }\end{array}$ & $\begin{array}{l}\text { Knowledge Scor } \\
\text { Knowledge Scor }\end{array}$ & $\begin{array}{l}\text { xplained by thi } \\
\text { xplained by thi }\end{array}$ & $\begin{array}{l}\text { Model } \\
\text { Model }\end{array}$ & \\
\hline
\end{tabular}

B: Regression coefficient, Beta: standardized regression coefficient, Adjusted R square: percent of the variance in the dependent variable explained by the independence.

Table 2: The General Linear Regression final model of Awareness Score

\begin{tabular}{|c|c|c|c|c|c|c|}
\hline \multirow[t]{2}{*}{$\begin{array}{c}\text { Demographic and clinical } \\
\text { characteristic }\end{array}$} & \multicolumn{2}{|c|}{$\begin{array}{c}\text { Un-standardized } \\
\text { Coefficients }\end{array}$} & \multirow{2}{*}{$\begin{array}{c}\begin{array}{c}\text { Standardized } \\
\text { Coefficients }\end{array} \\
\text { Beta }\end{array}$} & \multirow{2}{*}{$\begin{array}{c}\text { Significance } \\
\text { P value }\end{array}$} & \multicolumn{2}{|c|}{$\begin{array}{c}\text { Confidence Interval for B } \\
(95.0 \%)\end{array}$} \\
\hline & B & $\begin{array}{l}\text { Standard } \\
\text { Error }\end{array}$ & & & $\begin{array}{l}\text { Lower } \\
\text { Bound }\end{array}$ & $\begin{array}{l}\text { Upper } \\
\text { Bound }\end{array}$ \\
\hline Age & -.084 & .010 & -.355 & .000 & -.104 & -.064 \\
\hline Gender & -.729 & .268 & -.107 & .007 & -1.256 & -.203 \\
\hline Alcohol drinking & .485 & .301 & .069 & .108 & -.107 & 1.076 \\
\hline Education & 1.445 & .383 & .153 & .000 & .692 & 2.198 \\
\hline $\begin{array}{l}\text { Previous attendance of health } \\
\text { campaign on CVDs }\end{array}$ & 1.983 & .401 & .206 & .000 & 1.196 & 2.771 \\
\hline Weight & -.261 & .345 & -.031 & .449 & -.939 & .416 \\
\hline $\begin{array}{l}\text { Having family history of heart } \\
\text { Disease, hypertension, diabetes } \\
\text { or high cholesterol }\end{array}$ & 1.349 & .287 & .199 & .000 & .785 & 1.913 \\
\hline $\begin{array}{l}\text { Having any one of the following } \\
\text { chronic diseases: hypertension or } \\
\text { diabetes or high cholesterol }\end{array}$ & 1.011 & .336 & .130 & .003 & .351 & 1.671 \\
\hline Income & -.435 & .286 & -.064 & .129 & -.998 & .128 \\
\hline $\begin{array}{l}\text { Paying attention to eat healthy } \\
\text { diet }\end{array}$ & 1.015 & .274 & .149 & .000 & .478 & 1.553 \\
\hline Smokers & -.358 & .340 & -.049 & .293 & -1.025 & .310 \\
\hline $\begin{array}{l}\text { Ex-Smokers } \\
\text { Non-Smokers } \quad 0\end{array}$ & .392 & .440 & .035 & .373 & -.472 & 1.257 \\
\hline Practicing exercise & .583 & .355 & .067 & .101 & -.113 & 1.280 \\
\hline $\begin{array}{ll}\mathrm{R} \text { square } & =0.404 \\
\text { Adjusted R square } & =0.387\end{array}$ & & $\begin{array}{l}\text { f Variance } \\
\text { f Variance }\end{array}$ & $\begin{array}{l}\text { reness Score Exp } \\
\text { reness Score Exp }\end{array}$ & $\begin{array}{l}\text { ed by this Mode } \\
\text { ed by this Mode }\end{array}$ & & \\
\hline
\end{tabular}

B: Regression coefficient, Beta: standardized regression coefficient, Adjusted R square: percent of the variance in the dependent variable explained by the independence. 


\section{DISCUSSION}

This study indicated limitation in knowledge and awareness of CVDs and its risk factors among the general public in Penang, Malaysia. The developing of awareness programs to address the limitations in knowledge on CVDs is crucial for better outcome. However, perfecting the awareness programs demands finding factors predicting good knowledge and awareness. This will help targeting specific demographic groups that have limited knowledge and awareness.

In the final GLR model, there was an association between the knowledge and awareness with the level of attained formal education which is similar to results from developed and developing countries [18-20, 22, 23]. This global consistency reflects strong association between health literacy and the level of education. Health education in primary and tertiary schools is an important element in contemporary health promotion [24]. The developing of school-based awareness programs can positively affect lifestyle behaviour of teenage and young adults [24]. In this study, the general public considered television (TV) programs as their most preferred source of health information. Addressing people with lower education by attractive TV programs can increase their knowledge.

Suffering from CVDs and/or diabetes or having family history of it were predictive factors of knowledge. Similarly, studies in Pakistan and Jordan asserted this association [19, 22]. The findings of our study showed that paying attention to eat healthy diet is a predictive factor of knowledge and awareness on CVDs. There are consistency in the literature regarding this association [19, 23]. Although the difference in culture and food between the two countries North Ireland [23] and Jordan [19], the consistency with our findings imply that people's life style in terms of diet is affected by their health knowledge and perceptions. It is possible to infer that by increasing the general public awareness on the consequences of eating un-healthy diets might have positive effect on their habits.

The results demonstrated that females appeared to have insufficient knowledge and awareness on CVDs and its risk factors when compared to males. Certain literature showed no association between gender and knowledge on CVDs [18, 19, 23]. However, our findings supports the results of Muhamed et al. (2012). In that study, the researchers found that female attendants of primary care facilities had limited knowledge on CVDs [25]. Although efforts, it can be implied that awareness programs targeting females in Malaysia did not yet achieve their optimum goals [25].

Our results indicated no association between self reported level of health and the knowledge and awareness, which is consistent with other studies [19,23]. Our findings showed no association between personal income and the knowledge and awareness. In a study in the US, subjects living in rural areas are more likely to have lower knowledge on heart attack and stroke if they are not graduate from high school and are economically poor [26]. In Jordan, Mukattash et al. (2012) showed significant association between the socioeconomics and the knowledge on CVDs. However, another Malaysian study showed no association of income with knowledge on CVDs among females [20]. Such similarity in Malaysian context indicates that the income has no effect on the knowledge and awareness on CVDs in Malaysia.

Although practicing exercise was associated with knowledge and awareness in SLR, it was no longer predicting factor in the final GLR model. This is not in line with findings of Saeed et al. (2009) in India and Al Hamarneh et al. (2011) in North Ireland. Both studies indicated that practicing exercise is associated with knowledge on CVDs. It could be inferred from our findings that practicing exercise among the general public in Malaysia might be personal attitude which is not affected by health knowledge background.

There was no association between smoking and the level of knowledge in the final model. However, there was a significant difference in knowledge and awareness between smokers and non-smokers. This high lights that smokers attitude is not reflecting their knowledge. This might imply that awareness programs are informative but not convincing.

In this study, the general public was optimistic about the role of community pharmacist in the management and prevention of CVDs. The health care practitioners including community pharmacists have a great public health role in preventing CVDs. The community pharmacists can be considered an easy to access medical professional. Therefore, they can play a vital role along with the general medical practitioners (GPs) in developing future awareness programs. The role of community pharmacists is well perceived by the GPs in Malaysia [27]. Our findings in addition to the well perception of community pharmacist by GPs encourage more participation of community pharmacist in future public health awareness programs.

As every study has its own limitation, this study was limited by the participants' self reporting of their demographics and clinical characteristics. Further interventional studies might give the results more certainty. Although we have found that Indians have limited knowledge and awareness compared to Malays and Chinese, the small sample size of Indians in the study prevents the assertiveness of these findings. The small population of Indians compared to other races in Penang [28] and the convenience sampling method did not allow for larger presentation of the Indians in the study. Further studies focusing on specific demographic groups are required to assert these findings and hence build on the results in future awareness programs. 


\section{CONCLUSION}

It can be concluded that several factors could have a substantial impact on the general public knowledge and awareness on CVDs and its risk factors. The level of formal education constantly remains crucial factor. We recommend designing attractive awareness programs which use simple language to allow effective communication with people having lower education. Using T.V. programs and media to approach general public of different age, culture, race and educational level might be a suitable suggestion in this concern. As we demonstrated an association between people's awareness and their lifestyle in terms of eating healthy diet, more focus on the consequences of eating un-healthy diet can have a great impact on people's behaviour. The limitation in females' knowledge, draw attention that efforts to increase their awareness has to be increased. We suggest tailoring CVDs awareness programs particularly for females. The high knowledge and awareness of smokers, ex-smokers compared to non-smokers, gives indication that health care providers should not only focus on providing the information but also on making it attractable and convincing. This is crucial for achieving public health change towards better quality of life.

\section{REFERENCES}

[1] WHO, Global Atlas on Cardiovascular Diseases Prevention and Control. World Health Organization, World Heart Federation, World Stroke Organization, 2012.

[2] Laslett, L.J., et al., The worldwide environment of cardiovascular disease: prevalence, diagnosis, therapy, and policy issues: a report from the American College of Cardiology. J Am Coll Cardiol, 2012. 60(25 Suppl): p. S1-49.

[3] MOH, Ministry of Health: Health Facts 2013. 2013, Ministry of Health, Malaysia.

[4] WHO, Cardiovascular diseases (CVDs). 2012, Media Center, World Health Organization.

[5] Pearson, T.A., et al., AHA Guidelines for Primary Prevention of Cardiovascular Disease and Stroke: 2002 Update: Consensus Panel Guide to Comprehensive Risk Reduction for Adult Patients Without Coronary or Other Atherosclerotic Vascular Diseases. Circulation, 2002. 106(3): p. 388-391.

[6] Goldstein, L.B., et al., Guidelines for the Primary Prevention of Stroke: A Guideline for Healthcare Professionals From the American Heart Association/American Stroke Association. Stroke, 2011. 42(2): p. 517-584.

[7] Redberg, R.F., et al., ACCF/AHA 2009 Performance Measures for Primary Prevention of Cardiovascular Disease in Adults : A Report of the American College of Cardiology Foundation/American Heart Association Task Force on Performance Measures JACC, 2009. 54(14): p. 1364-1405.

[8] AHA, Metabolic Syndrome. American Heart Association, 2012.

[9] May, A.L., E.V. Kuklina, and P.W. Yoon, Prevalence of cardiovascular disease risk factors among US adolescents, $1999-2008$. Pediatrics, 2012. 129(6): p. 1035-41.

[10] Daviglus M1, T.G.A.A.-S.M. and et al., PRevalence of major cardiovascular risk factors and cardiovascular diseases among hispanic/latino individuals of diverse backgrounds in the united states. JAMA, 2012. 308(17): p. 1775-1784.

[11] Mohamud, W.N., et al., Prevalence of metabolic syndrome and its risk factors in adult Malaysians: results of a nationwide survey. Diabetes Res Clin Pract, 2011. 91(2): p. 239-45.

[12] Amplavanar, N.T., et al., Prevalence of cardiovascular disease risk factors among attendees of the Batu 9, Cheras Health Centre, Selangor, Malaysia. Med J Malaysia, 2010. 65(3): p. 173-9.

[13] Cheah, W.L., et al., A preliminary study on the prevalence of cardiovascular disease risk factors in selected rural communities in Samarahan and Kuching division, Sarawak, Malaysia. Malays J Med Sci, 2011. 18(2): p. 58-65.

[14] Thompson, D.R., Awareness of and attitudes to coronary heart disease among the public, patients and family members: the HELP study. Coronary Health Care, 1998. 2(1): p. 33-37.

[15] Bush, R.L., et al., Knowledge and Awareness of Peripheral Vascular Disease Are Poor Among Women at Risk for Cardiovascular Disease. Journal of Surgical Research, 2008. 145(2): p. 313-319.

[16] Kandula, N.R., et al., Knowledge gaps and misconceptions about coronary heart disease among U.S. South Asians. Am J Prev Med, 2010. 38(4): p. 439-42.

[17] Lambert, C., et al., The Relationship between Knowledge and Risk for Heart Attack and Stroke. Journal of Stroke and Cerebrovascular Diseases, 2012(0).

[18] Saeed, O., et al., Knowledge of modifiable risk factors of Coronary Atherosclerotic Heart Disease (CASHD) among a sample in India. BMC Int Health Hum Rights, 2009. 9: p. 2.

[19] Mukattash, T.L., et al., Public knowledge and awareness of cardiovascular disease and its risk factors: a cross-sectional study of 1000 Jordanians. IJPP, 2012. 20(6): p. 367-376.

[20] Yahya, R., R. Muhamad, and H.M. Yusoff, Association between Knowledge, Attitude and Practice on Cardiovascular Disease among Women in Kelantan, Malaysia. IJCRIMPH, 2012. Vol. 4(No. 8 ): p. 1507-1523.

[21] Santos, J.R.A., Cronbach's alpha: A tool for assessing the reliability of scales. Journal of extension, 1999. 37(2): p. 1-5.

[22] Jafary, F.H., et al., Cardiovascular health knowledge and behavior in patient attendants at four tertiary care hospitals in Pakistan--a cause for concern. BMC Public Health, 2005. 5: p. 124.

[23] Al Hamarneh, Y.N., G.E. Crealey, and J.C. McElnay, Coronary heart disease: health knowledge and behaviour. Int J Clin Pharm, 2011. 33(1): p. 111-23.

[24] Nutbeam, D., Health literacy as a public health goal: a challenge for contemporary health education and communication strateg ies into the 21st century. Health Promotion International, 2000. 15(3): p. 259-267.

[25] Muhamad, R., R. Yahya, and H.M. Yusoff, Knowledge, Attitude and Practice on Cardiovascular Disease among Women in NorthEastcoast Malaysia IJCRIMPH, 2012. Vol. 4(No. 1): p. 85-98.

[26] Swanoski, M.T., et al., Knowledge of heart attack and stroke symptomology: a cross-sectional comparison of rural and non-rural US adults. BMC public health, 2012. 12(1): p. 283.

[27] Hassali, A., et al., PROFESSIONAL TRAINING AND ROLES OF COMMUNITY PHARMACISTS IN MALAYSIA: VIEWS FROM GENERAL MEDICAL RACTITIONERS. Malaysian Family Physician, 2009. 4(2 \& 3)

[28] DOSM, Penang Statistics. 2012, Department of Statistics Malaysia. 